\title{
Everyday encounters with difference in urban parks: forging 'openness to otherness' in segmenting cities
}

\author{
Anna Barker (D), Adam Crawford* (D), Nathan Booth and David Churchill (D) \\ School of Law, Liberty Building, University of Leeds, Leeds, LS2 9JT, UK \\ ${ }^{*}$ Corresponding author. E-mail: a.crawford@leeds.ac.uk
}

\begin{abstract}
In a context of hyper-diversity and social polarisation, it has been suggested that public parks constitute crucial arenas in which to safeguard deliberative democracy and foster social relations that bind loosely connected strangers. Drawing on empirical research, we offer a more circumspect and nuanced understanding of the - nonetheless vital - role that parks can play in fostering civic norms that support the capacity for living with difference. As 'spaces apart', parks have distinctive atmospheres that afford opportunities for convivial encounters in which 'indifference to difference' underpins 'openness to otherness'. As places in which difference is rendered routine and unremarkable, the potency of parks for social cohesion derives from fleeting and unanticipated interactions and the weak ties they promote, rather than strong bonds of community that tend to solidify lines of cultural differentiation. Both by design and unintentionally, regulation and law can serve to foster or constrain the conditions that sustain conviviality.
\end{abstract}

Keywords: sociology of law; urban governance; public parks; encounters with difference; conviviality; atmospheres

\section{Introduction}

Some twenty-five years ago, Stuart Hall (1993, p. 349) argued that how we develop 'the capacity to live with difference' is the central question of our time. ${ }^{1}$ In light of fears over immigration, political extremism and violence, inequality and 'closed' forms of community, today Hall's forebodings appear ever-more prescient. In the context of hyper-diversity (Tasan-Kok et al., 2014) and where social and economic polarisation is overlain by insular cultural identities, mutual intergroup understanding is rendered increasingly vexed. Instead, dogmatism, intolerance and social division have become pervasive features of what Graham and Marvin (2001) have identified as 'splintering urbanism'. Contrastingly, in recent years, from within diverse disciplinary fields of political and constitutional legal theory, sociology and urban geography, public spaces - urban parks in particular - have been extolled as constituting crucial arenas in which to safeguard deliberative democracy, foster positive social relations and host encounters with difference that afford opportunities to construct social ties and civic norms that bind loosely connected strangers. This paper critically assesses these crossdisciplinary propositions with a focus on urban parks drawing on findings from an historically informed study exploring how people experience, use and interact within parks in Leeds. The project involved archival research, a citywide survey comprising 6,432 responses and 165 interviews with a range of stakeholders, including park users, 'Friends' groups, ${ }^{2}$ park managers and representatives

\footnotetext{
${ }^{1}$ In a series of lectures given at Harvard University in 1994, published posthumously, Hall (2017, p. 86) defined 'the problem of the twenty-first century... [as] the problem of living with difference' (emphasis in original).

${ }^{2 ‘}$ Friends' groups comprise of people who voluntarily work to maintain, improve and promote a park or green space. According to the National Federation of Parks and Green Spaces, there are over 6,000 'Friends' groups across the UK see: https://www.natfedparks.org.uk/.

(c) The Author(s) 2019. This is an Open Access article, distributed under the terms of the Creative Commons Attribution licence (http://creative commons.org/licenses/by/4.0/), which permits unrestricted re-use, distribution, and reproduction in any medium, provided the original work is properly cited.
} 
from various city services. We argue that many commentators have set unrealistic expectations as to the role that urban parks as public spaces can perform in a city. By contrast, we offer a nuanced and more circumspect than hitherto understanding of the - nonetheless vital and distinctive - role that public parks can play in fostering civic norms that support the capacity for living with difference in otherwise segmenting cities.

Since their creation in the nineteenth century, public parks have been designed, governed and regulated as distinct 'spaces apart' from the surrounding city for the purpose of facilitating co-mingling and co-presence among loosely connected strangers from diverse parts of society (Booth et al., 2019; Conway, 1991). The Victorian ideal of the park was explicitly tied to its social role in the construction of a 'civilised' community in the face of a swelling and increasingly heterogeneous urban population of the expanding industrial city, most evidently marked by social divisions of class through residential segregation (Churchill et al., 2018). On the acquisition of the first park in Leeds, Woodhouse Moor, in the 1850s, the Leeds Times newspaper reported:

'By this intercommunion and intermingling of classes, much mutual benefit and advantage to all parties will be attained; the rich and the very poor will begin to understand each other, and a great stride in the political civilisation will be the result.'

Through purposeful design and aesthetics, alongside copious byelaws, rules and codes of appropriate conduct and decorum, the Victorians sought to construct a distinctive and wholesome 'atmosphere' wherein visitors from different classes of urban society were permitted to relax, play and mix together in edifying ways in the park. Loose face-to-face interactions in these normatively ordered social environments, it was supposed, would serve the constitution of a civic public and remake 'the fractured social bonds of the city' (Booth et al., 2019).

Aspects of the Victorian ideal continue to shape how parks are conceived, administered, used and imagined today (Barker et al., 2019). The recent parliamentary inquiry into public parks underscored their importance as places that are 'open and available to all ... as a social space for people of different ages or from different backgrounds to come together' (House of Commons, 2017, para. 17). Hence, there is an enduring expectation that public parks constitute common places of social diversity in which difference is not essentialised, but rendered a routine and unremarkable feature of everyday encounters. Influenced by their rich heritage and fashioned in and through everyday experiences over the past 150 years, we argue that parks - purposefully designed, regulated and managed largely as inclusive spaces of recreation ${ }^{4}$ - have distinctive atmospheres that afford opportunities for conviviality. Parks are 'ambient places' that satisfy a 'compulsion of proximity' (Boden and Molotch, 1994) in the sense that parks facilitate a need felt by individuals to interact with others in face-to-face settings. Yet, they are distinctive places of co-mingling and co-presence that do not necessarily require people to engage in the same activities, directly interact or share a collective identity, but afford opportunities for face-to-face observation of, and encounter with, difference. They are social and communal places, yet also places where people seek solitude and privacy; they combine co-presence and physical proximity with relative anonymity. Parks express their own rhythm and temporality that are distinct from the sounding city. The logic of 'pedestrianism' that governs the streets orchestrating 'orderly movement', circulation and flow (Blomley, 2011, pp. 3-4) contrasts with the atmosphere of parks as places for people to enjoy, relax and dwell. Hence, we contend that the potency of parks in which to forge conviviality derives from fleeting face-to-face encounters, loose and unanticipated interactions and the weak ties that they promote, rather than the strong affective bonds of community that bind groups together and tend to solidify lines of difference and cultural closure. We argue that these characteristics of parks simultaneously reveal limitations on their capacity to foster intercultural interactions and

\footnotetext{
${ }^{3}$ Leeds Times, 14 June 1856, p. 2.

${ }^{4}$ We do not mean to suggest that parks are free from a sociospatial politics of inclusion and exclusion that infuse all public spaces.
} 
mutual understanding at a deeper level. Hence, our argument for the role of parks in fostering social ties and civic norms is more circumspect than prior historical and other contemporary propositions.

Following Sloterdijk, we contend that atmospheres can function as 'modes of conviviality', producing 'a resonance between those who live together' (cited in Bille et al., 2015, pp. 37, 34). Crucially, the affective atmosphere of a park can be fostered or undermined by forms of design, use, law, regulation and governance, whether intended or otherwise. Where conditions are conducive, the prevailing atmosphere plays a vital and distinctive role in constituting parks as safe, accessible and hospitable places for diverse users to co-mingle and interact in which 'indifference to difference' underpins an 'openness to otherness'. In this Journal, Patrignani (2018, p. 374) has argued that the issue of 'living together' in territorially situated human interactions accompanied with basic shared values is both 'a timely issue' and one that 'creates challenges for law'. She asserts: 'Nowadays, living together needs to be renegotiated in a situation of plurality of cultural lifestyles. Taken-for-granted social norms, cultural forms of expression and of social conversance are confronted with alternatives whose alterity can fascinate, but also perturb' (Patrignani, 2018, p. 374).

Our discussions and empirical data seek to shed light on the nature of social relations, bonds and values fashioned in everyday encounters with difference in parks with which formal authorities and laws must engage and navigate among a plurality of semi-autonomous normative orderings (Moore, 1973). Parks are places in which social relations and accompanying civic norms are produced, performed and reproduced; these unwritten and informal forms of 'law' shape and redirect in different manners the behaviour of people, alongside explicit rules and written laws. In Silbey's (2005, p. 332) terms, this entails exploration of the (re)production of civic norms that constitute 'the iceberg of legality [which] lies submerged within the taken-for-granted expectations of mundane life'. Parks, as distinct spaces in which human interactions are territorially situated, not only inform the prevailing social norms, experiences and expectations therein, but are simultaneously shaped by the wider regulatory norms in which they are situated; that both govern and infuse them. The prevalent atmosphere of a park is both constitutive of and constituted by civic norms. So, too, it is legally determined, in that law allows certain collective affects and 'sensory options to come forth while suppressing others' (Philippopoulos-Mihalopoulos, 2013, p. 36). When the law 'dissimulates its presence' in space, Philippopoulos-Mihalopoulos argues, it becomes 'atmosphere' (2018, p. 4). For him, 'space cannot be understood without law'; indeed, 'law and space are folded into each other: they are co-emerging, co-constituting and co-evolving' (Philippopoulos-Mihalopoulos, 2018, pp. 1, 11) - a tautological relationship that he calls 'lawscape' (Philippopoulos-Mihalopoulos, 2015). Building upon these insights, we deploy the notion of atmosphere to capture the distinctive normative and affective frames that parks - as 'spaces apart' - afford encounters with difference.

Our arguments are organised into four parts. The first considers contemporary propositions regarding the role of the public park within the city. Namely, we explore the aspirations for parks as public fora and sites of expressive activity that are strongly connected to deliberative democracy through their openness to all before critically reviewing the role of social encounters in public space in countering prejudice and forging a civic culture out of difference. In doing so, we outline and advance a notion of conviviality as an atmosphere and an affect through which to explore the capacity of urban encounters in parks to engender civic norms. The second part provides empirical insights from research in Leeds to illustrate and develop the arguments presented. The third part outlines the parameters, we suggest, parks can play in fostering convivial relations and the conditions and 'affective atmospheres' (Anderson, 2009) that provide for meaningful encounters with others. We conclude by suggesting that, both by design and unintentionally, regulation and law can serve to foster or constrain the conditions that sustain conviviality.

\section{Celebrating social encounters: contemporary propositions on the role of the public park}

There is a long-standing and rich tradition from within diverse disciplinary fields celebrating the role played by social encounters in urban public spaces for forging sociality and a deliberative democratic 
politics. In recent years, contemporary propositions provide a frame in which the constitutive role of the park within the city might be located.

\subsection{Public parks as bastions of deliberative democracy}

Recently, Sunstein (2017) has championed public spaces in cities - parks in particular - as vital bastions of 'deliberative democracy', in the face of forces that are undermining democracy and segmenting populations. The contemporary challenge, he argues, comes from the social filtering that engenders self-referential 'echo chambers' and 'information cocoons'. The Internet and social media have enabled platforms that foster indirect impersonal transactions that lack co-presence (i.e. face-to-face interactions) and allow people to filter and control what they see, hear and experience, as well as whom they interact with. Additionally, powerful communications providers filter and classify people based on mining information in the traces of our interactions with technologies. Ever-evolving algorithms constitute the channels that congeal social filtering. The result is growing political fragmentation, social and cultural polarisation, and extremism.

By contrast, Sunstein (2017) argues that streets and parks - as key 'public fora' where diverse people congregate - encourage people to see and hear a wide range of topics, ideas and expressions of difference, all of which serve a well-functioning democracy. Crucially, they do so even if people would not have chosen to experience them in advance, if they had known. When you visit a park,

it is possible that you will have a range of unexpected encounters, however fleeting or seemingly inconsequential ... you cannot easily wall yourself off from contentions or conditions that you would not have sought out in advance, or that you would have avoided if you could ... these exposures help promote understanding and in that sense freedom.' (Sunstein, 2017, pp. 39-40)

Sunstein (2017, p. 34) draws on the American constitutional doctrine of public forum as articulated by the Supreme Court in the late 1930s, ${ }^{5}$ which, he argues, reflects - brings to life even - 'the most general constitutional ideal of all: deliberative democracy'. Heterogeneous public fora - where they work well improve the quality of deliberations, and hence the outcomes. In so doing, they mollify the effects of practices of self-insulation in which people cocoon themselves from the concerns and opinions of others, by providing speakers with free access to an audience and audiences with free access to differing opinions. Rather like the idealised Victorian vision, which was only ever partially realised in everyday practices (Churchill et al., 2018), the public forum - as an ameliorative space for safeguarding deliberative democracy - may provide an ideal around which to constitute a renewed raison d'être and rallying cry to secure parks of the future.

\subsection{Forging hybrid cultures through contact}

In both historic and contemporary forms, much scholarship that celebrates the public spaces of the city as key sites for forging sociality and new hybrid cultures draws - implicitly or explicitly - on Allport's (1954) 'contact hypothesis', which purports that contact is an effective means of countering prejudice. Contact reduces uncertainty and feelings of anxiousness by producing a sense of knowledge, familiarity or trust between strangers. From this perspective, diversity reduces ethnocentric attitudes and fosters out-group trust and solidarity. Allport identified four special conditions that he believed facilitated favourable intergroup contact: equal status between the groups in the situation; common goals; intergroup co-operation; and the support of authorities, law or custom. Despite positive conclusions that contact works and its effects are 'boosted' by these conditions (Pettigrew and Tropp, 2006; Hewstone, 2009), interventions directed at ethnic or racial prejudice generate weaker effects (Paluck et al., 2018).

\footnotetext{
${ }^{5}$ Hague v. Committee for Industrial Organisation, 307 U.S. 496 (1939). In England and Wales, Arts 10 and 11 of the European Convention on Human Rights provide the corresponding legal context.
} 
Valentine (2008, p. 325) rightly warns of the dangers of 'worrying romanticisation of urban encounter' and the 'naïve assumption that contact with "others" necessarily translates into respect for difference'. She questions what kinds of encounter might produce 'meaningful contact' (see also Mayblin et al., 2016). By this, she means 'contact that actually changes values and translates beyond the specifics of the individual moment into a more general positive respect for - rather than merely tolerance of - others' (Valentine, 2008, p. 325). Valentine (2008, p. 332) concludes from her research on White people with ingrained prejudices: 'Positive encounters with individuals from minority groups do not necessarily change people's opinions about groups as a whole for the better with the same speed and permanence as negative encounters.' She suggests that encounters do not 'destabilise' deeply rooted majority prejudices 'based on narratives of economic and/or cultural victimhood'. Yet, in expecting transformations in attitudes of respect, Valentine may be holding the bar too high as to what encounters in public spaces might contribute to a politics of connectivity.

\section{Conviviality: atmosphere, affect and public parks}

Sharing Valentine's concerns with identifying the nature of and the conditions for meaningful contact, we deploy conviviality as a lens to understand the role that encounters in public parks can play in fostering civic norms. The 'convivial turn' (Neal et al., 2013; Wise and Noble, 2016) captures a new orientation from which to analyse encounters with difference that focuses on the 'being together of strangers' (Young, 1990, p. 237). Etymologically, conviviality stems from the Latin term convivir meaning 'to live with' but this means more than simply co-existing in a plural society. Gilroy (2004, p. xv) first characterised the solidarities born of habitual interaction in multicultural localities as 'conviviality'. To elucidate further, 'conviviality', Gilroy argues,

is a social pattern in which different metropolitan groups dwell in close proximity but where their racial, linguistic and religious particularities do not - as the logic of ethnic absolutism suggests they must - add up to discontinuities of experience or insuperable problems of communication.' (Gilroy, 2006, p. 40)

For Gilroy, conviviality rejects integrationist assumptions of ethnic and cultural assimilation. Rather, convivial culture renders racial and ethnic differences unremarkable and ordinary: they become commonplace (2006, pp. 39-40). Instead, people 'discover that the things which really divide them are much more profound: taste, lifestyles, leisure preferences'. As such, conviviality serves as a deliberate departure from traditional concepts of 'community' that depend on close bonds of identity. Following Young (1990, p. 239), the erotic attraction to the other the city spaces instantiate is precisely the obverse of community'. Rather than ties of belonging, convivial relations are premised on unspectacular transgressions of existing, ascribed racial and ethnic identities that emerge from mundane routine practices, 'habits' and 'habituations' (Noble, 2013). There are close parallels with Amin's (2013, p. 3) civilities of 'indifference to difference', Wise's (2013, p. 40) posture of 'simply letting be' and much of the contemporary emphasis on a cosmopolitan ethic (Appiah, 2006). What is alluded to here is the 'strength of weak ties' (Granovetter, 1973). In park life, our research suggests, identifications are more likely to be looser and rooted in shared practices and neighbourliness, rather than in bonds of homophily - more concerned with getting along (as social lubricant) than with togetherness (as social glue). In Putnam's (2000) terms, they foster bridging rather than bonding social capital.

Convivial multiculture is 'atmospheric' (Bissell, 2010). Conviviality has atmospheric and affective qualities that go beyond simply the festivities, joviality and bonhomie associated with social gatherings and events. As Neal et al. (2013, p. 316, emphasis added) assert: 'conviviality is more open, less demanding and defensive, and more transient. It can be felt and experienced in the most momentary encounters as well as in more sustained social relations.' Following Wise and Velayutham, we deploy conviviality as 'an atmosphere and an affect' that is 'intimately related to a sense of becoming' (2014, p. 407). Atmospheres lie beyond the realm of individual experience and can exert a force on 
those surrounded by them. Atmospheres capture 'collective affects' (Anderson, 2009), providing the shared ground connecting people, their feelings and emotions, and places. They constitute 'a fundamental aspect of the human experience of the world' and form 'an important part of the identities and conceptualisations of landscapes, architecture and homes' (Bille et al., 2015, p. 31). They are 'located in-between experience and environments' and intersect the objective/subjective and the material/ immaterial (Böhme, 1993). As Bille and colleagues (2015, p. 32) note, an atmosphere is 'not simply the subjective feel of a room or a situation, nor is it an objectively observable state of the physical environment'. Rather, atmospheres are commonly defined by their sensory, affective and emotional dimensions, as providing a 'sense of place'. Their affective, material and temporal dimensions make them an anticipated or expected quality of a place and simultaneously shape collective experience. Atmospheres do not just happen spontaneously, but need to be constructed and engendered; they can be 'staged', 'enhanced', 'transformed', 'intensified', 'shaped' and otherwise manipulated (Böhme, 2006).

We now turn to provide empirical insights from research in Leeds to illustrate and develop the arguments presented.

\section{Leeds parks: empirical vignettes}

Leeds is a post-industrial city in the north of England with a population of over 750,000. People from over 140 minority ethnic groups represent approximately 17 per cent of the population. Leeds City Council $(2009$, p. 2$)$ manages 4,000 hectares of public green space, including seventy parks, and articulates an inclusive vision of parks as high-quality accessible spaces 'at the heart of the community'. ${ }^{6}$ Our citywide residents' survey (Barker et al., 2018) ${ }^{7}$ found that visiting parks is an integral part of everyday life for most people. Some 91 per cent had visited a park in the preceding year and, on average, people visited five parks per year throughout the city. Half of park users visited their main park at least once a week. Estimated adult visits to parks in Leeds in 2016 totalled nearly 45 million. Moreover, respondents mostly derived positive experiences from their last visit. Some 77 per cent of park visitors reported having a 'very pleasant' experience (on a four-point scale). Indeed, only 4 per cent identified having a 'somewhat' or 'very' unpleasant experience. Our analysis revealed that parks that met quality standards were associated with significantly higher levels of satisfaction and use. This attests to the importance of public investment and proactive management by authorities, and by volunteers, ${ }^{8}$ in constituting the atmosphere of a public park so that it feels safe, accessible and welcoming for diverse users to co-mingle and interact.

In addition to the survey, we interviewed visitors to three Victorian parks in Leeds, all of which met quality standards: Woodhouse Moor (WM), Cross Flatts Park (CFP) and Roundhay Park (RP). Woodhouse Moor is the closest large park to the city centre and the second most visited park, attracting nearly 3 million adult visits per year according to our survey. The surrounding area comprises varied socio-economic neighbourhoods with an eclectic mixture of housing, including back-to-back terraces without gardens. Situated near two universities and several colleges, the atmosphere of the park is strongly influenced by fluctuations across the student calendar. The volume of student use of the park has generated, among long-term residents, fears of dominance as well as debates about appropriate use, behaviour and conduct. It is regulated by a Public Space Protection Order, prohibiting the consumption of alcohol. A 'Unity Day' held on the Moor was established in the aftermath of disorder in the mid-1990s, as an annual event to bring together the diverse local communities in celebration.

\footnotetext{
${ }^{6}$ At the time of our fieldwork, in 2016, the city's seven major parks held the Green Flag status, which is the benchmark standard for well-managed recreational outdoor spaces across the UK and around the world (http://www.greenflagaward.org.uk). Some 41 of 63 community parks met an equivalent quality standard.

${ }^{7}$ The survey was available online between June and November 2016 and sent to a random sample of 20,000 households across the city, stratified in proportion to ward population and weighted according to the Index of Multiple Deprivation.

${ }^{8}$ In Leeds, time given by volunteers to the upkeep and maintenance of parks and green spaces is equivalent to 109 full-time workers per year.
} 
Cross Flatts Park is a community park in the south of the city. It services a predominantly workingclass, deprived and ethnically diverse locality that has struggled with intergroup tensions. The atmosphere of the park has transformed over recent decades from a 'no-go' area and physical divide between distinct communities to a thriving space with an active 'Friends' group. It was first judged to meet quality standards in 2010. However, drug dealing and vandalism promote continued concerns about safety. Since the early 2000s, the park has hosted a variety of events that intentionally seek to bring communities together, including the annual Beeston Festival and Sunday bands.

Roundhay Park is one of the biggest city parks in Europe. It is, by far, the most visited park, drawing tourists, people from the wider region and the local population of predominately middle-class residents. It is a classic civic park and traditionally a place of grand show and ceremony. It is home to a major visitor attraction known as Tropical World and hosts major events such as the Magic Lantern Festival and the World Triathlon.

Collectively, they provide a range of canvasses with potentially different atmospheres across which to explore the possibilities and challenges for forging sociality through encounters with difference. Semi-structured interviews were held with sixty-two adult park users aged eighteen years old to people within their nineties, with a minimum of twenty interviews from each park. It also draws from ten focus groups with seventy-three young people; all were aged fifteen to nineteen, except one was undertaken specifically with university students in their early twenties (as popular users of Woodhouse Moor). These were conducted between September 2016 and April 2017. In total, we spoke with an equal number of male and female park users. Some ninety-one park users interviewed self-identified as White British and forty-four as Black, Asian or other minority ethnic group.'

In what follows, empirical insights from the project are deployed to illustrate and interrogate the wider conceptual arguments. We elucidate and explore experiences and views of encounters with difference that are perceived as fostering constructive or convivial outcomes. We do not deploy conviviality to suggest that encounters in parks are inevitably, always or even largely convivial. Nor is it to suggest in any sense that the convivial outweighs the conflictual. Rather, we are interested in exploring the constitutive feature and character of convivial encounters and in beginning to interrogate the ways conviviality and conflict variably intertwine in everyday park life. Inescapably, encounters with 'others' can reinforce intergroup segmentation and cross-cultural antipathies. However, our research suggests that most people, most of the time, derive pleasant experiences from visiting their park and witnessing its diversity. After illustrating that parks are one example of commonplace diversity, we use one case-study to illustrate how changes to the atmosphere of a park engendered through reforms to the design, regulation and animation of the space can help promote intergroup recognition over time.

\subsection{Constructing an atmosphere that is open to all: diversity, co-presence and variegation}

For some, parks are essential meeting places for social networks or necessary places in which to pursue personal routines; for others, they are sites of enjoyment and uncertain pleasure and, for yet others, they are merely conduits or shortcuts across which to traverse. According to our interviewees, the diversity of people who visit parks is seen as one of its key attractions - or 'seductions' in Young's terms - and a distinctive atmospheric quality. Hence, parks can represent one example of 'commonplace diversity' where there is an 'ethos of mixing', albeit one that is 'paralleled by the acceptance of more separate lives regarding private relations' (Wessendorf, 2013, p. 408). Key to this is that most local-authority parks are public spaces that are free to enter and openly available to all. ${ }^{10} \mathrm{~A}$ hallmark across time has been the presumption of free public access, recognised in section 10 of the Open Spaces Act 1906, which asserted that parks are to be held and administered in trust to allow ...

\footnotetext{
${ }^{9}$ This significant overrepresentation is largely due to the disproportionate (as against the city population) number of minority ethnic young people present in the focus groups.

${ }^{10}$ Nonetheless, access can be withdrawn by local-authority landowners.
} 
the enjoyment thereof by the public'. As the following reflections illustrate, public parks are valued precisely because they promote an affective atmosphere that is defined by its openness to all:

'I'm always really, really pleased that a very wide cross-section of the population chooses to come here and choose to make it their park.' (16RP)

'Whenever we're there you do see a wide range of people from all different backgrounds; whether it be Southeast Asian, or the Indian subcontinent, or you get Eastern Europeans use it to hang around and loiter in ... everyone seems to be there.' (37CFP)

The visible, and specifically multicultural, diversity that is evident in such spaces creates a feeling of difference as normal. The lens of conviviality takes us beyond a 'politics of recognition' - which is always in danger of essentialising difference - towards a normalisation of difference and a quest for alternative (non-essential) points of social connectivity, including an insistence on the universal worth of each person based on shared humanity.

Even where diversity comes with costs to the atmosphere of a park - noise or congestion - it is, nonetheless, generally celebrated:

'It's a common - rich, poor, everyone goes there, so we've got the whole of society. I'm troubled by loud people occasionally but it's not a real problem. I think it's good that it is used by a lot of people.' (18RP)

Accordingly, parks are used by many different 'publics', each with distinct interests and (often deeply held) views about appropriate conduct. Hence, they afford considerable opportunities for competition and conflict. Planned variegation by local authorities - akin to forms of use-based zoning - offers possibilities for constructing an atmosphere of a park as open to all by hosting and welcoming difference though diverse uses structured spatially and temporally (Barker et al., 2019). Forms of design and regulation built into the materiality of the park and its byelaws ${ }^{11}$ can constitute a way of maximising cultural and lifestyle preferences in park use while minimising possible conflict. As Low and colleagues (2005, p. 198) argue: 'The social interaction of diverse groups can be maintained and enhanced by providing safe, spatially adequate territories for everyone within the larger space of the overall site.' Interviewees clearly felt that forms of planned variegation, as well as tendencies towards self-segregation, can provide a means of accommodating different needs and demands within the park:

'Well, it all sounds so stereotypical but all the older people are in the allotment area and the bowls court, all the dog walkers are on the paths, all the little kids are at the play area; it tends to be the school kids who are on the basketball courts and then the older lads are on the skate parks, and then the students are just sat on the field drinking. So yeah, I do think the presence of the different facilities works in its favour because everyone has their own area. Whether anyone is frustrated that they can't get to the skate park, but they don't fit in the demographic, I don't know but I've never seen it to be an issue.' (22WM)

Through the park atmosphere, direct contact is not always a necessary condition for feeling connected to other users of parks: 'The act of sharing a public space such as a park or plaza, where people come together in their mutual affinity for the place itself, can also create "a connection to others without

\footnotetext{
${ }^{11}$ For instance, 'model byelaws' for local authorities in England and Wales include 'designated areas' from which certain groups or uses are excluded. See https:/www.gov.uk/government/publications/pleasure-grounds-public-walks-and-openspaces-model-byelaw-2 (accessed 20 August 2019).
} 
interaction"' (Neal et al., 2015, p. 473). Like Simmel's (1971) account of the 'stranger', parks foster a relationship in which people become members of a spatial or use-related practice more so than a social group. Just as Simmel's stranger does not want to be assimilated, park visitors enjoy the state of being 'in-between': of remoteness and proximity, closeness and distance, in defined spaces where social worlds meet.

It was felt that forms of variegation support the shared use of space by those with competing interests while also permitting a wide range of park users (including those engaging in deviant behaviours) to be co-present:

'That group of lads [drug dealing] stay in an area. It's quite a segregated park, so you get one area that certain people go in. Therefore, most people bringing their children in to use the toddlers' playground would never, ever venture down to that area of the park. It's funny how in a park that's not that large, you might never cross paths with an element that you would feel intimidated by.' (39CFP)

This interviewee points to how unwritten norms of interaction, tendencies towards self-segregation and forms of planned variegation combine to shape and direct relationships and associations among those who inhabit the park. It illustrates potentially distinctive atmospheres of parks in being able to facilitate encounters between diverse users where exclusion is not inevitable (Young, 1990). Here, the focus is less on the value of intergroup 'contact' per se and more on the conditions under which 'indifference to difference' becomes the premise for and prelude to encounters that foster an 'openness to otherness'.

Whilst variegation may be seen as a form of social 'filtering' (in Sunstein's terms), it can nonetheless provide an important means of co-existence and conflict management that contributes to the 'staging' (Böhme, 2006) of a particular atmosphere defined by its openness to all:

'It minimises it [possible conflict], because of the quadrants people can find their own space in there [the park]. You can have a Muslim family sat in their own little piece and next door over the park there's something else going on, but they don't need to interact with each other with regards their own space .... It's open for everyone.' (27WM)

As these examples testify, diverse users willingly expose themselves to and embrace subtle forms of face-to-face encounters with others and value free expression while avoiding direct forms of verbal exchange and interactions. Some explicitly opposed Sunstein's image of the park as a deliberative forum for ideas and opinions given its implications for unsettlingly the atmosphere of a park:

'I'm glad that there isn't somewhere that people can go and stand and give their political views. So it's not like Hyde Park [Speakers' Corner in London]. I think that should be excluded from the park .... So it should be a politically neutral area and a safe place to be.' (31RP)

Overt forms of 'free expression' that intrude upon others' enjoyment and some behaviours perceived to be antisocial were felt to jar with the circulating park norms of live and let live and do as you would be done by. Furthermore, where variegation works well, it fosters a well-used space that provides for forms of group 'civil inattention' (Goffman, 1972) that co-create safety through numbers:

'I think the fact that places are used by a lot of different people for a lot of different purposes make it a safer place ... the more users there are, the more it's cared for and the safer it is.' (28WM)

Variegated parks may foster connections between diverse communities, but only to a limited degree given its segmented form. By hosting a variety of uses and users - who can see and be seen by 
others - parks reflect and embed difference and diversity rather than a shared common experience. People may co-mingle and 'rub along' (Watson, 2009), as they engage in their separate uses, but social interactions are likely to be limited to observation of others with few opportunities for routinely negotiating difference through direct verbal contact. Hence, we argue that the variegated design of many parks and the tendency for self-segmentation, on the one hand, may limit the capacity of these spaces to provide opportunities for thick forms of engagement and encounter but, on the other hand, are valuable precisely because of this, in that they enable different groups to share space, see each other and form an indifference to difference.

Nevertheless, parks also present opportunities not just to see and be seen by others, but also may foster spontaneous, unanticipated verbal social encounters: 'You meet lots of different people ... you're sat down in the park you don't know who you're going to speak to, and that's why parks are so important' (27WM).

The same person went on to illustrate this spontaneous capacity to connect erstwhile strangers through informal and loosely organised mutual interests and practices in the park:

'We used to walk up to the park and not even know the teams at the park and say: "Can we join in?" ... before you realise you've got 22 a side. That's what the park does: it draws people in to actually enjoy.' (27WM)

As the above testifies, convivial atmospheres may be built upon connective experiences of, and encounters within, a shared physical space - namely the park - whereby 'the strangeness of strangers goes out of focus and other dimensions of a basic sameness can be acknowledged and made significant' (Gilroy, 2004, p. 3).

Furthermore, our interviewees provided diverse examples of everyday acts of politeness, civility and kindness between strangers in parks - moments that Thrift (2005, p. 147) describes as providing 'reservoirs of hope' that might 'leak out into the wider world':

'I love the fact that it's a public space. I don't want it to myself. I love the fact that people use it and that ... you can go there and meet people and talk to people and have that social contact with people without having to formally meet up with anyone.' (8RP)

Thicker forms of engagement - such as conversations with others - may be more likely between those who share practices or activities. Runners participating in the weekly parkrun engaged in mutual congratulations and conversation after the event. Such reciprocal affective support and social aspects of parkrun have been found to extend people's social networks (Wiltshire and Stevinson, 2018):

'I think it [the park] does have a massive role in the community perhaps without people realising because I speak to people that I wouldn't speak to on a day-to-day basis. If I didn't go [to parkrun] I wouldn't be speaking to much older men and women of all different backgrounds and little kids. If I didn't go there ... I'd just be in the university bubble.' (22WM)

Similar sentiments were expressed by dog walkers and by parents with children in relation to interactions in playgrounds.

\subsection{Bridging communities}

Whilst many respondents said that parks help to foster a 'sense of community', this was often interpreted either as collective practice (as above) or as a pride in locality rather than shared values: 'It's like a place where people can congregate, and you see the life in the community, and it makes me feel like I'm part of a community' (53CFP). 
The atmosphere of a park facilitates 'getting along' in the context of difference rather than forging a shared community of 'togetherness':

'I don't necessarily think it [the park] fostered one kind of all-connected community, not that many really have, it was a home for lots of micro-communities ... if that park wasn't there you wouldn't have that thing drawing those communities together .... You would lose the centre of it that connects the various communities at Hyde Park.' (25WM)

Another resident highlighted the park as a neutral community space in which difference is both accommodated and rendered normal, in a context of light engagement and co-presence:

'Beeston in some respects there's lots of challenges but there's lots of collaboration, lots of interdependence. And I think parks and green spaces are part of that as creating those spaces where people can come out from behind their fences and behind their front doors and see one another, and be with one another, even if they're not interacting with them.' (41CFP)

According to some, co-existence and co-presence can foster mutual recognition with a normative quality that makes intercultural tolerance and appreciation a loose form of obligation: 'You have a true mix of all the people who live in the area, using the park together and relating to each other in that they just accept each other's presence' (38WM).

Atmospheres can define moments for individuals (Bille et al., 2015). Certain 'moments of recognition' stand out as especially memorable or as having greater transformative implications. For some, the park atmosphere constitutes a dramatic representation of difference and depiction of harmonious diversity:

'I remember, probably about 30 years ago, there was one sunny afternoon in summer and there were students there, but there were a group of Irish guys playing hurling and a group of Muslim women sitting in a group talking, an assortment of local people and university people on the playground, and I just remember thinking: "This is just such a lovely meeting place for the area". (24WM)

Such moments and the encounters they afford offer the potential to 'disrupt easy labelling of the stranger as enemy and invites new attachments' (Amin, 2002, p. 970). Furthermore, observing may itself have beneficial implications:

'you can see other people using the park, like I can see the kids using the play area, I can see all the skaters using the skate-park, and even if I'm not interacting with them just that visibility is quite important.' (22WM)

The 'thrown-togetherness' that public spaces afford people in the city, to which Massey (2005, p. 181) has drawn attention, should not be confused with the more stifling forms of 'togetherness' that Jacobs (1961, p. 62) lambasts: 'This ideal is that if anything is shared among people, much should be shared.' ${ }^{12}$ The 'thrown-togetherness' that parks induce is not social capital as glue that expresses itself in a shared sense of belonging and identity within communities, but rather constitutes looser social capital as a lubricant facilitating relations between people of different social groups (Putnam, 2000). It allows people to 'get along' or sometimes - where difference becomes or equates with difficulty to 'rub along'. As Cotterrell (2017, p. S35) notes, 'emotional ties can be strong but volatile', whereas weaker, 'instrumental ties of common interest can be transient, ephemeral, and changeable' (emphasis

\footnotetext{
${ }^{12}$ Jacobs (1961, p. 62) goes on to assert: “"Togetherness," apparently a spiritual resource of the new suburbs, works destructively in cities. The requirement that much shall be shared drives city people apart.'
} 
in original); they may lack sustainability that endures across time and in the face of powerful countervailing forces.

\subsection{Transforming the atmosphere of a park: fostering intergroup recognition over time}

Parks can feel like desolate, fearful places. Conversely, parks can exhibit virtuous circles whereby increased levels of use foster perceptions of safety. Cross Flatts Park provides a useful case-study of how a park atmosphere can be transformed to help foster intergroup recognition over time aided by processes of formal and informal social regulation. It was widely held by park managers and users alike that the park has transformed over recent decades from a 'no-go' area that constituted a physical and symbolic boundary between distinct communities living either side of the park to a thriving communal space where diverse users congregate and co-mingle in (mostly) convivial ways. The following interviewees reflected this consensus:

'In '99 ... people would talk about the park as kind of Gaza strip and a no-go zone ... the park was very much a dividing line across the communities. But I think that's no longer the case.' (37CFP)

'It was known as the number one ... most dangerous park in Leeds ... the unsociability problems were out of control ... it was a park that local residents wouldn't go into ... it is quite a success story compared to other parts of Leeds and other cities ... [now] there is harmony there.' (Community safety officer)

Looking back to the 1980s and 1990s, interviewees recalled significant issues around vandalism, crime and antisocial behaviour in which informal social controls and formal management had broken down: 'There was no fence around the park... which made it a very dangerous place and it was just horrible. The community had turned its back on it but so had the Parks Department' (Councillor).

Improvements to the design and condition of the park (and surrounding area) in the late 1990s and 2000s and changing perceptions of safety were vital in this turnaround, giving visitors a confidence to use the park, rather than avoid it as a fearful and unsafe place. This transformation was achieved with and through the communities, notably via the active role of the 'Friends' group, supported by the park managers and municipal services. Wider changes to the visible policing of public spaces and legal measures to tackle antisocial behaviour introduced by the Crime and Disorder Act 1998 were also thought to have played a role in making the park a safer space for people to use and enjoy. Of these, controversially perhaps in that it introduced dynamics of exclusion, the erection of boundary fencing at the turn of the millennium was credited as a defining moment in enabling the communities to reclaim the park, preventing its use for non-human traffic, joyriding and abandoned motor vehicles:

'The putting up of the fencing around the park was quite a big issue ... it was totally unfenced at that time, so we got burnt out cars, cars being driven in, motorbikes having a free run of the park. So, it wasn't very safe, and it was unpleasant.' (55CFP)

Nonetheless, it took active local engagement before social perceptions of the ingrained reputation began to change. The 'Friends' work in establishing events and activities in the park that bring diverse communities together and encourage use helped to change perceptions:

'The main reason we started doing Bands in the Park ... was because of the perception of the park, even though it had moved on [in terms of condition] the perception was it was still a horrible park, and it takes years to get the perception changed .... So that's why we started doing brass bands in the park, so we were getting the oldest community to come in and to go: "Oh this is quite nice here". And then they'd go out and tell everybody else.' (Councillor) 
The planning of the Sunday summer bands by the 'Friends' was deliberately outward-looking in that they sought to offer music that appealed to diverse local audiences. The atmosphere created by such events has been acknowledged as bringing together people who might otherwise not mix, thus creating a host of unanticipated convivial encounters that were recalled and remembered with striking affection for the social mixing that happened:

'We've had so many funny afternoons in the sun where you've got children and loads and loads of old people in the community come out and sit on the chairs .... Obviously some of the alcoholics in the area come out as well. Quite often when you've got quite country, folky bands, they'll get up and dance, and the children like to get up and dance. Some afternoons stick in my memory where you'll get the boozy people with their cans of super-strength dancing with the local kids. It's a really lovely atmosphere, but it brings parts of the community [together] who probably avoid each other normally.' (39CFP)

Annual multicultural events like the Beeston Festival have also successfully promoted positive social interactions between communities. The fact that people began to use the park more regularly has made it a safer place, both objectively and subjectively. However, this has been a hard-fought and longterm process of building intergroup trust and mutual recognition:

'Cross Flatts has got a real great community spirit to it now .... Yeah, and the playgrounds now are used as opposed to just abused; the tennis courts and the basketball courts are getting used by locals ... it is really quite a nice area to be in. It's an area where it welcomes diversity, it welcomes other communities.' (Community safety officer)

Although the park faces continuing challenges, it is now heralded by many park managers and residents as a revitalised space that plays a significant role in fostering social relations in the locality. As one resident underscored: 'It's only because of the park that the community has got so good. I don't think it would be otherwise' (49CFP).

Nonetheless, it is recognised that the kinds of 'collective affects' (Anderson, 2009) that the park has promoted fall far short of the strong bonds of solidarity that some might wish for:

'Typically people come to Beeston Festival with people they know, they have a nice time, they maybe have a few new interactions with people on stalls or whatever ... but it's interesting to think here about how you can take those events to the next stage and start to really create not just a sense of community but actually genuinely community interaction and interdependence and solidarity.' (41CFP)

While there is evidence that communities that may otherwise live 'parallel lives' (Cantle, 2001) now co-exist in the park, this shift is not one of cultural transformation, but of mutual co-existence in which self-segregation still plays a role in normative ordering:

'So, you have predominantly white British using the more formal rose garden and play area, Eastern Europeans and Asians using the sports courts, and then at the bottom are your Afro-Caribbean with the cricket. And we've tried to glue those communities together. They don't. In the park, I think, it's working okay.' (Park manager)

Some interviewees felt that the park's atmosphere and potential as a site of social mixing remain precarious. There are fears that a decline in condition or increase in crime might undermine its recent revival. It is widely appreciated that continued involvement by communities and authorities will be needed to sustain the atmosphere of the park as a convivial place of co-mingling: 'It's very, very 
intensively used, and that is going to need some careful management and investment to keep that working' (Park manager).

It was acknowledged that, if the park were to return to its prior unloved and unsafe state or somehow no longer be openly accessible, this would undoubtedly impact adversely on intercultural mixing, which, as one interviewee noted, 'might increase any tensions between the two communities' (50CFP).

In this context, the park has played a role in fostering mutual recognition as an ethic with greater transformative implications: 'It's probably made the community more aware of each other and made them think and look at each other and come together as a community ... I think it really has helped' (Community safety officer).

\section{Conditions for conviviality}

In increasingly segmenting cities, the 'coordination and stable integration of social life seems not only more elusive, contingent, and fragile but also more essential' (Cotterrell, 2017, p. S36). In contrast to Sunstein's contention that parks perform a deliberative democratic role as places of free expression, we argue that parks are places in which people are open to encounter difference but are largely semiliminal places of escape and recreation, not necessarily places to expect the discussion or airing of differing opinions. Following Sunstein, our findings support the idea that the atmosphere of parks provides a distinctive counterpoint to compartmentalised and self-referential social environments. They open a gateway into a liminal space of ambiguity and disorientation in which conventional ordering and social sifting are suspended or, at least, loosened. Indeed, parks are 'messy' places, in the sense that Nowotny (2017, pp. 12-13) uses the term, in which 'unpredictability is the name of the game'. Combining the spatial, aesthetic and affective dimensions of co-presence, the atmosphere of a park affords the possibility to connect people to objects, nature or persons in ways that may seem incompatible or unanticipated. Moreover, they are valued by many precisely because they enable these different possibilities.

Yet, to tie parks too closely to achieving such deliberative outcomes, even if only as ideals, risks overextending their actual social value and masking their potential role in fostering sociality in less instrumental ways. The idea of public parks as places of deliberative debate rather selectively appropriates the image of Hyde Park's Speakers' Corner in London, which serves as 'the mother symbol of the modern liberal polity's ostensible commitment to free speech and assembly' (Cooper, 2006, p. 754). By contrast, Cooper $(2006$, pp. 755,772$)$ argues that even this icon of deliberative democracy is not 'a radical cultural space' of inclusivity and equality, but might rather be understood as the intersection between debate and 'foolery, bawdiness and the transgression of social hierarchy' in which strangers and regulars interact. Additionally, our findings suggest that this image of the park as deliberative forum is one that park visitors generally eschew, while willingly exposing themselves to more subtle forms of encounters with others through recreational and leisure practices, public events and festivals in parks that foster a shared affinity with place (Neal et al., 2015).

Across all our parks, the ideal of a welcoming and peaceful public park often belies the reality of competing claims to space that frequently inform territorial and cultural conflicts. Power struggles and conflicts over the control and possession of public spaces within parks were evident not only between people and groups of differing cultures and ethnicity, but also between different age groups and interest associations. Contact can breed resentment, frustrations and simmering friction. Valentine (2008, p. 323) is undoubtedly correct to highlight the need 'to pay more attention to sociospatial inequalities and the insecurities they breed, and to unpacking the complex and intersecting ways in which power operates' in public spaces. Hence, management strategies that provide a level of quotidian security constitute a (pre)condition of well-managed public spaces that afford ways of living together with cultural diversity in the contemporary city. As we have seen, well-used parks convey a liberal invitation of welcome and foster a sense of security - through safety in numbers - even where this natural surveillance and capable guardianship are provided by strangers. Indeed, urban parks - like other large urban 
spaces where different people come together - provide not only opportunities for relaxing, learning and recreation, but also 'places where interpersonal and intergroup cooperation and conflict can be worked out in a safe and public forum' (Low et al., 2005, p. 3). As one interviewee noted of low-level disagreements: 'that's not really conflict, that's just people rubbing along together isn't it and accepting [differences]?' (8RP).

Unlike Sunstein's focus on speech, we share with Watson the view in relation to markets that

'limited encounter between social subjects where recognition of different others through a glance or gaze, seeing and being seen, sharing embodied spaces in talk or silence, has the potential to militate against the withdrawal into the private self or private realm'. (Watson, 2009, p. 1581)

This parallels Goffman's (1972) characterisation of 'civil inattention' as a tacit principle governing social relations in public, where one person recognises another person's presence and their claims to a public space through glances or brief eye contact but does not seek a sustained interaction. Such fleeting and bounded interaction rituals serve to 'signal mutual regard and the absence of threat' (Manning, 1992, p. 13). ${ }^{13}$ Parks offer ample opportunities for the unobtrusive and peaceful scanning of others in ways that allow interactions. As such, 'people watching' - seeing and being seen - is an accepted feature of park use. We argue that everyday meaningful encounters with difference can provide 'learning opportunities' or 'moments of recognition' that serve as a counterfoil to contemporary trends towards social segmentation. In drawing together our findings, we offer the following conditions as constituting the parameters for our interpretation of the social role that parks might play in forging an 'openness to otherness' by way of loose relations between strangers.

First, the nature of the 'encounter' is not reducible to speech or direct interaction or contact, but can be - and usually is - non-verbal, observed and indirect displays of behaviour, activities or interaction. Indeed, being together in the shared atmosphere of a park can create 'a structure of feeling made more significant because it does not require dialogic interaction' (Neal et al., 2015, p. 470). For our purposes, encounters occur or unfold in a shared time-space configuration that constitutes 'co-presence'.

Second, the encounter itself is unplanned or spontaneous - albeit the 'atmospheres' conducive to fostering the occurrence may themselves have been planned or designed. Following Peattie (1998, p. 248), conviviality 'can be encouraged by the right rules, the right props, and the right places and spaces'. Convivial co-mingling requires active facilitation, planning, mediation and responsive regulation to enable diverse people to get along (Fincher and Iveson, 2015, p. 23; Barker, 2017). The quality and inclusivity of parks - as reflected in standards of good management, facilities and upkeep - will be conducive to fostering convivial encounters.

Third, the encounter itself is perceived by at least one individual as 'meaningful'; it has an intersubjective quality with regard to the recognition of difference. In Young's (1990, p. 240) terms, it prompts an 'understand[ing] that there are other meanings, practices, perspectives ... that one could learn and experience something more and different by interacting with'. However, the same exposure, interaction or contact may be experienced and interpreted differently by different actors.

Fourth, the encounter engenders a dimension of generalisability or scalability beyond the instant moment to different times and places; in Valentine's (2008, p. 325) words - noted above - it 'translates beyond the specifics of the individual moment'. Scalability may derive from the transferability of the norms or values implied and/or from the incremental, cumulative effects of similar repeat encounters over time. Hence, the meaningfulness of the encounter may derive from the accumulation of linked 'moments' as a result of which difference may become increasingly rendered mundane and unremarkable.

Finally, the values and norms imparted through social learning and recognition are those that render difference ordinary, and foster greater intercultural and intergroup understanding that may, over time, serve to increase trust. The outcomes of such encounters need not result in a greater communality

\footnotetext{
${ }^{13}$ Yet, 'civil inattention' as an everyday strategy of negotiating order among strangers can also reduce feelings of responsibility for the well-being of others.
} 
through shared values or group membership, but rather mutual recognition that itself may offer looser ties of affiliation or connection based on shared activities and practices (Gilmore, 2017).

\section{Conviviality, atmosphere and law}

Conviviality focuses attention on a complex interpersonal capacity to be at ease in public spaces in the presence of diversity and form an openness to otherness. But, as Wise and Velayutham point out, 'conviviality is more than the interpersonal' (2014, p. 408). A range of factors - material, structural, spatial and legal - mediate park users' experiences and support (or potentially constrain) the atmospheres of social environments, as well as the ambience and interactions therein, that promote conviviality. Hence, design and materiality are deemed to be of central importance in fostering convivial spaces (Peattie, 1998; Shaftoe, 2008; Bates, 2018). Less has been said about the role of law and regulation and its relationship to conviviality. The role of law both through presence and absence, we suggest, is to foster atmospheres that are conducive to conditions of conviviality.

However, law is not simply an instrument working on social relations, but is also a set of conceptual categories and narratives that help construct, communicate and give meaning to social relations. From this perspective, law's context is fashioned in and through the routine, locally repeated enactments or practices of what cumulatively comes to constitute social institutions, structures and the 'atmospheres' that provide the shared ground connecting people, their feelings and emotions with the spaces they occupy or pass through, (re-)producing 'collective affects that are not reducible to the individual bodies that they emanate from' (Anderson, 2009, p. 80). Importantly, atmospheres are not juxtaposed as 'authentic' or 'genuine' in contrast to purposeful staging, design or regulation. Rather, they occupy a tense relation in which 'orchestrations of space are often central to sociality, politics and aesthetics' (Bille et al., 2015, p. 31). Atmospheres are forged through the constitutive interactions of social norms and formal legal orderings; they are the affective artefacts of intentional designs and unintended consequences.

Philippopoulos-Mihalopoulos (2015, p. 4) suggests that the lawscape - the interconnection between law and space that expresses atmosphere - 'takes place as a play of visibilisation and invisblisation'. This he illustrates as follows:

'A no-smoking sign in a public space is a visibilisation of the law, but the free, open space of an art gallery performs an invisibilisation of the law ... a façade of ambling and seemingly unconstrained movement, free from legal presence.' (Philippopoulos-Mihalopoulos, 2015, p. 4)

He argues that 'at various points a lawscape appears more or less legal, or more or less spatial'. Parks are evidently spaces where written byelaws and unwritten rules, civic norms and principles of civility coalesce, shaping the atmospheres of spatiality and directing in different ways the behaviours of those who use them. Law can serve to constrain and to liberate through both presence and absence. Excessive law can stifle. As Philippopoulos-Mihalopoulos (2018, p. 11) notes: 'Space ... requires an invisibilisation of the law ... we need to forget about the law ... when we walk around the city.'

In parks, however, it is not simply law's visible absence or presence that informs the conditions for a convivial atmosphere, but also its capacity to mediate a loosening of behavioural regulation with a hospitable promotion of openness to difference, in ways that become routinised and rendered mundane, as if part of the (park) furniture. Such atmospheres in parks need to be engendered and safeguarded in minimally non-intrusive ways that are responsive to civic norms that enable difference to feel welcome without being essentialised. The task of law and regulation is to render difference normal and to preserve the liminal expectations that parks afford. In this light, parks share qualities akin to a 'semi-autonomous social field' (Moore, 1973, p. 720) where a multiplicity of norms and forms of law co-exist and which

'has rule-making capacities, and the means to induce or coerce compliance; but it is simultaneously set in a larger social matrix which can, and does, affect and invade it, sometimes at the invitation of persons inside it, sometimes at its own instance.' 
If conviviality is about the capacity of individuals to thrive in combination with others unlike themselves, then the relationship of law to conviviality is to foster and promote the conditions and environments for such encounters to occur. Formal legal regulations do more than reflect or encode what is otherwise normatively constructed through micro-social everyday interactions and encounters with difference. Law shapes and is shaped by such civic norms and social interactions. The relationship of law to conviviality, in essence, is to promote and foster the 'generative capacities of public spaces' (Koch and Latham, 2012, p. 515), including their free public access and open availability to all. This begs empirical questions about how, in specific places at a particular time, law and regulation can best enable constructive, sociable outcomes that are likely to foster openness to otherness. How might laws better enable light interactions that support new identities and forms of social bridging that render ethnic and cultural difference unremarkable? Focusing on the everyday life of citizens, as we have sought to do, allows us to begin to interrogate the ideals and principles that legal institutions and norms might do well to accommodate, enact and sustain.

We suggest that insights from research on everyday practices of living, interacting and negotiating with difference - directly or indirectly - in a variety of public spaces needs to play a more central role, informing local and national policies and practices. Yet, we are acutely aware that the thrust of the arguments presented here and the allied need to attend to the conditions and atmospheres conducive to the micro-dynamics of intercultural recognition and sociality are at odds with the dominant forces of securitisation and changes in land use that inform much contemporary urban politics that find form in new legal tools and regulations (Crawford and Hutchinson, 2016). As Low et al. (2005, p. 1) argue: 'we are facing a different kind of threat to public space - not one of disuse, but of patterns of design and management that exclude some people and reduce social and cultural diversity.' Parks need an accompanying politics of connectivity that supports local and city-level governance that embeds forms of 'mediated conviviality' (Barker, 2017), rather than technologies of preventive exclusion, social discipline and 'banishment' that too readily engender sterile or overtly orderly atmospheres that breed a culture of mistrust and fear of 'others'. This is precisely why, as Amin (2010, p. 3) recognises, 'a politics of encounter requires active intermediation by third parties, managed interaction or common projects in order to undo settled behaviour, build interdependence or common purpose, catalyse positive feelings'.

\section{Conclusion}

Certain everyday places - through their affective atmospheres and the nature of interactions they foster emerge as 'convivial spaces' (Nowicka and Vertovec, 2014, p. 347). Public parks, we contend, afford distinctive spaces apart from the city that surrounds them with opportunities for fostering conviviality. However, parks do not constitute spaces for safeguarding deliberative democracy or forging tight bonds of 'community' (political, cultural or otherwise) and should not be held to such expectations. Rather, parks host and express diversity - they foster an atmosphere in places where difference is normalised and rendered mundane. Under certain conditions, parks can enable convivial encounters with difference that foster greater appreciation of diversity. Our research illustrates that the atmosphere of a park can nurture and support convivial use and intergroup social mixing. Conversely, parks can be places of intergroup tensions that become feared and avoided. Back argues that focusing on such crucibles of everyday life

'allows us to attend to the inherent liveliness of social life and its time signatures ... it makes us take the mundane seriously and ask what is at stake in our daily encounters with neighbours or the people we brush past.' (Back, 2015, p. 821)

This we have sought to do, highlighting how the social ties, norms and affect constituted in and through urban parks have considerable salience for a contextualised understanding of social norms, regulation and law - one that is rooted in, and works up from, empirical studies of everyday encounters and the civic bonds, values and practices they foster (Cotterrell, 2017). 
We have argued for a kind of 'cosmopolitan' ethic for public parks that combines both recognition that people have obligations to others that stretch beyond those with whom we have close social ties to strangers and mutual recognition for social and multicultural difference (Appiah, 2006). In the context of parks, this resonates with Appadurai's (2013, p. 198) notion of a 'cosmopolitanism from below' one that begins 'close to home and builds on the practices of the local, the everyday, and the familiar' but imbues an 'urge to expand one's current horizons of self and cultural identity and a wish to connect with a wider world in the name of values that, in principle, could belong to anyone and apply in any circumstance'.

Nonetheless, the current precarious juncture in the history of parks, the spectre of encroaching privatisation and continued absence of a statutory legal duty on UK local authorities to provide and maintain parks to recognised quality standards (Heritage Lottery Fund, 2016; House of Commons, 2017) have severely reduced the scope for public parks to occupy any central role in constituting a civic realm of the future. If urban parks are to constitute spaces of habitual encounter with difference in which to develop forms of intergroup recognition and intercultural understandings, we are left with new challenges. To return to where we started, for Hall (2017, p. 174), 'the question is not who we are, but who we can become' (emphasis in original). In debates about how we might constitute a civic culture that enables city dwellers to live confidently with difference, we contend that it is as important to appreciate the limitations of public spaces as the harbingers of cosmopolitan hospitality and bastions of deliberative democracy as to explore and extol the vital opportunities they present for constructive future social relations.

Acknowledgements. This paper draws from an AHRC grant: 'The future prospects of urban parks: the life, times and social order of Victorian public parks as places of social mixing' (Ref: AH/N001788/2). We are grateful to Dr Jose Pina-Sánchez for assistance with the survey weighting adjustment. An earlier version was presented at an international workshop on 'Constituting Cities' at the Faculty of Law, University of New South Wales, 10-11 May 2018 and benefited greatly from valuable insights and feedback from delegates, especially Luke McNamara, Kurt Iveson, Marion Roberts and Alison Young. All named authors contributed significantly to the intellectual development of the article and approved the final version published. The first two named authors took the lead in framing and writing the paper.

\section{References}

Allport GW (1954) The Nature of Prejudice. Reading, MA: Addison-Wesley.

Amin A (2002) Ethnicity and the multicultural city. Environment and Planning A 34, 959-980.

Amin A (2010) Cities and the Ethic of Care for the Stranger. York: Joseph Rowntree Foundation.

Amin A (2013) Land of strangers. Identities 20, 1-8.

Anderson B (2009) Affective atmospheres. Emotion, Space and Society 2, 77-81.

Appadurai A (2013) The Future as Cultural Fact. London: Verso.

Appiah KA (2006) Cosmopolitanism: Ethics in a World of Strangers. New York: WW Norton \& Co.

Back L (2015) Why everyday life matters. Sociology 49, 820-836.

Barker A (2017) Mediated conviviality and the urban social order. British Journal of Criminology 57, 848-866.

Barker A, Churchill D and Crawford A (2018) The Leeds Parks Survey: Final Report. Leeds: University of Leeds. Available at https://futureofparks.leeds.ac.uk/wp-content/uploads/sites/26/2018/03/Leeds-Parks-Survey-Full-Report.pdf (accessed 24 November 2019).

Barker A et al. (2019) Park futures: excavating images of tomorrow's urban green spaces. Urban Studies. Available at https:// doi.org/10.1177/0042098019875405 (accessed 24 November 2019).

Bates C (2018) Conviviality, disability and design in the city. The Sociological Review 66, 984-999.

Bille M, Bjerregaard P and Sørensen TF (2015) Staging atmospheres. Emotion, Space and Society 15, 31-38.

Bissell D (2010) Passenger mobilities: affective atmospheres and the sociality of public transport. Environment and Planning D: Society and Space 28, 270-289.

Blomley N (2011) Rights of Passage. London: Routledge.

Boden D and Molotch H (1994) The compulsion to proximity. In Friedland B and Boden D (eds), Nowhere: Space, Time and Modernity. Berkeley: University of California Press, pp. 257-286.

Böhme G (1993) Atmosphere as the fundamental concept of a new aesthetics. Thesis Eleven 36, 113-126.

Böhme G (2006) Architektur und Atmosphäre. Munich: Wilhelm Fink Verlag.

Booth N et al. (2019) Spaces apart: public parks and the differentiation of space in Leeds, 1850-1914. Urban History, forthcoming.

Cantle T (2001) Community Cohesion: A Report of the Independent Review Team. London: Home Office. 
Churchill D, Crawford A and Barker A (2018) Thinking forward through the past: prospecting for urban order in (Victorian) public parks. Theoretical Criminology 22, 523-544.

Conway H (1991) People's Parks: The Design and Development of Victorian Parks in Britain. Cambridge: Cambridge University Press.

Cooper D (2006) 'Sometimes a community and sometimes a battlefield': from the comedic public sphere to the commons of Speakers' Corner. Environment and Planning D 24, 753-775.

Cotterrell R (2017) Theory and values in socio-legal studies. Journal of Law and Society 44, S19-S36.

Crawford A and Hutchinson S (2016) Mapping the contours of 'everyday security': time, space and emotion. British Journal of Criminology 56, 1184-1202.

Fincher R and Iveson K (2015) Conviviality as an ethic of care in the city. In Gibson K, Rose DB and Fincher R (eds), Manifesto for Living in the Anthropocene. New York: Punctum Books, pp. 23-27.

Gilmore A (2017) The park and the commons: vernacular spaces for everyday participation and cultural value. Cultural Trends 26, 34-46.

Gilroy P (2004) After Empire: Melancholia or Convivial Culture? Abingdon: Routledge.

Gilroy P (2006) Multiculture in times of war. Critical Quarterly 48, 27-45.

Goffman E (1972) Relations in Public. London: Penguin.

Graham S and Marvin S (2001) Splintering Urbanism. London: Routledge.

Granovetter M (1973) The strength of weak ties. American Journal of Sociology 78, 1360-1380.

Hall S (1993) Culture, community, nation. Cultural Studies 7, 349-363.

Hall S (2017) The Fateful Triangle: Race, Ethnicity, Nation. Cambridge, MA: Harvard University Press.

Heritage Lottery Fund (2016) State of UK Public Parks 2016. London: HLF.

Hewstone M (2009) Living apart, living together? The role of intergroup contact in social integration. Proceedings of the British Academy 162, 243-300.

House of Commons (2017) Public Parks: Seventh Report of Session 2016-17, HC 45. London: House of Commons.

Jacobs J (1961) The Death and Life of Great American Cities. New York: Random House.

Koch R and Latham A (2012) Rethinking urban public space. Transactions of the Institute of British Geographers 37, 515529.

Leeds City Council (2009) A Parks and Green Space Strategy for Leeds. Leeds: Parks and Countryside Department.

Low S, Taplin D and Scheld S (2005) Rethinking Urban Parks: Public Space and Cultural Diversity. Austin: University of Texas Press.

Manning P (1992) Erving Goffman and Modern Sociology. Stanford: Stanford University Press.

Massey D (2005) For Space. London: Sage.

Mayblin L, Valentine G and Andersson J (2016) In the contact zone: engineering meaningful encounters across difference through an interfaith project. The Geographical Journal 182, 213-222.

Moore SF (1973) Law and social change: the semi-autonomous social field as an appropriate subject of study. Law and Society Review 7, 719-746.

Neal S et al. (2013) Living multiculture: understanding the new spatial and social relations of ethnicity and multiculture in England. Environment and Planning C: Government and Policy 31, 308-323.

Neal S et al. (2015) Multiculture and public parks. Population, Place and Space 21, 463-475.

Noble G (2013) Cosmopolitan habits: the capacities and habitats of intercultural conviviality. Body \& Society 19, $162-185$.

Nowicka M and Vertovec S (2014) Comparing convivialities: dreams and realities of living-with-difference. European Journal of Cultural Studies 17, 341-356.

Nowotny H (2017) An Orderly Mess. Budapest: Central European University Press.

Paluck EL, Green SA and Green DP (2018) The contact hypothesis re-evaluated. Behavioural Public Policy. Available at https://doi.org/10.1017/bpp.2018.25 (accessed 24 November 2019).

Patrignani E (2018) Overcoming essentialisation: a comparative study of 'living-together' conceptions. International Journal of Law in Context 14, 374-395.

Peattie L (1998) Convivial cities. In Douglas J and Friedmann J (eds), Cities and Citizens. Chichester: Wiley, pp. $247-252$.

Pettigrew TF and Tropp LR (2006) A meta-analytic test of intergroup contact theory. Journal of Personality and Social Psychology 90, 751-783.

Philippopoulos-Mihalopoulos A (2013) Atmospheres of law. Emotion, Space \& Society 7, 35-44.

Philippopoulos-Mihalopoulos A (2015) Spatial Justice: Body, Lawscape, Atmosphere. London: Routledge.

Philippopoulos-Mihalopoulos A (2018) And for law: why space cannot be understood without law. Law, Culture and the Humanities. Available at https://doi.org/10.1177/1743872118765708 (accessed 24 November 2019).

Putnam R (2000) Bowling Alone. New York: Simon and Schuster.

Shaftoe H (2008) Convivial Urban Spaces. London: Routledge.

Silbey S (2005) After legal consciousness. Annual Review of Law and Social Science 1, 323-368.

Simmel G (1971) The stranger. In Levine DN (ed.), On Individuality and Social Forms. Chicago: University of Chicago Press, pp. 143-149. 
Sunstein C (2017) \#Republic: Divided Democracy in the Age of Social Media. Princeton, NJ: Princeton University Press.

Tasan-Kok T et al. (2014) Towards Hyper-diversified European Cities. Utrecht: Utrecht University.

Thrift N (2005) But malice aforethought: cities and the natural history of hatred. Transaction of the Institute of British Geographers 30, 133-150.

Valentine G (2008) Living with difference: reflections on geographies of encounter. Progress in Human Geography 32, 323-337.

Watson S (2009) The magic of the marketplace. Urban Studies 46, 1577-1591.

Wessendorf S (2013) Commonplace diversity and the 'ethos of mixing'. Identities 20, 407-422.

Wiltshire G and Stevinson C (2018) Exploring the role of social capital in community-based physical activity: qualitative insights from parkrun. Qualitative Research in Sport, Exercise and Health 10, 47-62.

Wise A (2013) Hope in a land of strangers. Identities 20, 37-45.

Wise A and Noble G (2016) Convivialities: an orientation. Journal of Intercultural Studies 37, 423-431.

Wise A and Velayutham S (2014) Conviviality in everyday multiculturalism. European Journal of Cultural Studies 17, 406-430.

Young IM (1990) Justice and the Politics of Difference. Princeton, NJ: Princeton University Press.

Cite this article: Barker A, Crawford A, Booth N, Churchill D (2019). Everyday encounters with difference in urban parks: forging 'openness to otherness' in segmenting cities. International Journal of Law in Context 15, 495-514. https://doi.org/ $10.1017 /$ S1744552319000387 